\section{Miocene Stratigraphy}

\section{- An Integrated Approach}

\section{Edited by A. Montanari, G.S. Odin and R. Coccioni}

Elsevier, 1997. 694 pages, hardbound, NLG 395.00/US\$247.00, ISBN 0-44482498-7.

The Miocene is an epoch which witnessed many extraordinary events in the Cenozoic period, such as the upheaval of the AlpineHimalayan orogenesis, global climatic and environmental changes, the progressive closure of the Western Tethys Ocean resulting in the isolation of the Mediterranean Sea from the rest of the world's oceans, and ultimately the appearance of hominids in Africa. Abundant and colorful stratigraphical documents reveal that the Miocene represents a prelude to modern geologic times when the biologic and physical environment of our planet reached a stage similar to today's world. Therefore, applying an integrated approach to the study of the Miocene stratigraphy is certainly an important and meaningful task. A. Montanari, G.S. Odin and R. Coccioni, encouraged by the successful results of the Miocene Columbus project (MICOP) and supported by the MICOP workshop, undertook this task. Through their substantial editorial efforts to ensure internal consistency and cross-checking the considerable interdisciplinary data documented by 80 contributors, this big volume of "Miocene Stratigraphy" was accomplished within the short time span of a couple of years.

The volume has six parts (from A to F) and includes 37 chapters, with 777 references cited. Index of authors, index of paleontology, index of geography and geology are given. In addition, a list of all 80 contributors is attached.

For the purpose of accomplishing the research on the Miocene integrated stratigraphy with the consideration of a global practice, application of the concept of GSSP (Global Stratotype Section and Point), interdisciplinary investigation and use of modern approaches are emphasized. Supported by the International Commission on Stratigraphy, IUGS, this new concept (GSSP) is aimed at giving additional information to supplement historical stratotypes. Therefore, in applying this concept, a thorough knowledge of historical stratotypes, together with the use of most recent stratigraphical tools in the study of classic sections, and a knowledge of where to locate the GSSP sections for proposal, are required. Four historical areas, i.e., Aquitaine and Rhone Valley in France, and the Italian Piedmont and Sicily are taken as the main study regions. The reason is that the Miocene sedimentary sequences there are represented mainly by sections of continuous shallow marine sediments, fossiliferous with the intercalation of vocaniclastic layers, which are suitable for the study of integrated stratigraphy. In Part A of this volume, a definition of the chronostratigraphic unit-stage is given, historical stratotypes of all the Miocene stages in mainly the above-mentioned four historical areas are reviewed, a method elaborating stages of global use defined by a combination of historical stratotypes and GSSP is introduced and the available data concerning historical stratotypes from the same areas, together with some additional data from nearby areas considered utilizable for stage definition, are presented in accordance with the European Subdivision of the Miocene (i.e., the Lower Miocene Aquitanian Stage and Burdigallian Stage; the Middle Miocene Lanphian Stage and Serravallian Stage; the Upper Miocene Tortonian Stage and Messinian Stage).

Parts C, D and E systematically record a series of studies relevant to subseries of the Lower, Middle and Upper Miocene respectively. Representative Miocene sections or sequences in the four historical areas and a few localities in Japan and boundaries between epochs (Oligocene/Miocene and Miocene/Pliocene boundaries), subepochs (boundaries between the Lower, Middle and Upper Miocene) and stages located within these sections or sequences are studied by applying the concept of integrated stratigraphy, or, in other words, by using multiple stratigraphic tools including lithostratigraphy, biostratigraphy, magnetostratigraphy, chemostratigraphy and geochronology. Of these, at least one univocal tool, either biostratigraphy or geochronology, is used to provide a chronological attribution for the sedimentary sequence. Since the application of stratigraphical concepts depends on the nature of available geological records and the latest Miocene deposits bear strong resemblance to those of the Quaternary, climatostratigraphy is considered to be a tool available for the integrated stratigraphical study of the latest Miocene deposits.

In Part F, as the conclusive portion of this big volume, a brief review of the methods and techniques applied to the Miocene geochronological studies and results obtained is given. Technical details of age dating for involved laboratories are introduced, with emphases on an awareness of and measures for minimizing analytical uncertainties and on interlaboratory comparisons and critical cross-checking of diverse individual results, in order to increase the precision of age-dating.

Finally, taking the subdivision of the Miocene originally defined in Europe (i.e., the six stages grouped in couples, constituting the three subunits of Lower, Middle and Upper Miocene, as stated above) as a foundation, the definition of stages is discussed according to the data available in Part A of this volume, with the priority of defining more precisely the limits between stages.
And in redressing defects caused by a common tendency to locate chronostratigraphic boundaries simply in coincidence with some biostratigraphic signals, boundaries between subepochs and stages are more reasonably located. On this basis, numerical ages of boundaries between Miocene Stages and the duration of each of the stages are estimated geochronologically. As a result of the interdisciplinary study of biostratigraphy and geochronology, potential sections for locating the GSSP relevant for boundaries of all the Miocene stages, and those more preferable for use as auxiliary sections, are proposed.

Because the time span of the duration of the Middle Miocene is much shorter than the Early or Late Miocene, this leaves little room for the two middle Miocene stages, and as the Lanphian stage represented by the historical stratotype shows more regional (Mediterranean) than global applicability, it is proposed in this book that the chronostratigraphic column be simplified for easier global applicability, by defining a single global stage covering the whole time represented by the Langhian and Serravallian stages, which would be nominated the "Anconian" after the name of a nearby city. As a consequence, this would result in a modified new chronostratigraphic subdivision of the Miocene (in ascending order, the Early Miocene represented by the Aquitanian Stage and the Burdigalian Stage; the Middle Miocene represented by a single Anconian Stage; and the Late Miocene represented by the Tortonian Stage and the Messinian Stage).

The publication of this volume is really a praiseworthy achievement. Focusing on applying the concept of GSSP through interdisciplinary approaches, the book is a good example of the study of integrated stratigraphy, that is not only of value to stratigraphers, paleontologists, and biostratigraphers, but is also useful to magnetostratigraphers, chemostratigraphers as well as geochronologists who dedicate their efforts to a global chronostratigraphy.

Almost all the stratigraphic information and a very rich account of the geohistory of the Miocene in the western Tethyan domain are provided. A large reference collection attached is helpful to experts in different geological fields. This book has many strengths and few weaknesses, but there are a few typographical errors in the text. As a comment, I would like to point out that the last paragraph in page 621 under the heading of "Aquitanian/Burdigalian boundary" actually refers to the Oligocene/Miocene boundary, not to the Aquilanian/Burdigalian boundary.

\section{Professor Hao Yichun}

Member of the Chinese Academy of Sciences China University of Geosciences

29 Xueyuan Road

Beijing 100083

China 


\section{Global karst correlation}

\section{Edited by Yuan Daoxian and Liu Zaihua}

Science Press, Beijing and New York, and VSP BV, Utrecht and Tokyo, 1998. 308pp. plus 70 plates, hardback, US\$90.00. ISBN 7-03-006837-8. ISBN 1-880132-32-X. ISBN 90-6764-286-X.

Project 299 "Geology, Climate, Hydrology and Karst Formation" was a UNESCO/IUGSsupported project of the International Geological Correlation Program (IGCP). It was the first project dedicated to karst problems under the auspices of the IGCP since its initiation in 1972. This book constitutes the final report of IGCP 299 that operated over the period 1990 to 1994. Earlier publications of the project are listed in Appendix 4. The findings reported in this book are of special interest to those involved in karst science and responsible for karst resource management.

Karst is distinctive because of its unusual and often spectacular surface topography, caves, extensive subterranean drainage systems, very large springs, major groundwater reservoirs, fragile ecosystems, and special vulnerability to pollution. It is developed on especially soluble rocks such as carbonate lithologies, particularly limestones and marble, which cover about $12 \%$ of the continental area of the Earth, but is also found on even more soluble evaporite rocks, such as gypsum and rock salt which also cover large areas.

Project 299 was ambitious, as the title of this book indicates, involving nothing less than global correlation on a planet where we are still trying to find out where all the karst is and what its characteristics are. My first impression upon reading the list of contents and scanning the chapters is that this volume constitutes an up-to-date and more comprehensive version of an earlier book that was edited by Herak and Stringfield (1972) entitled "Karst: Important Karst Regions of the Northern Hemisphere", the greatest weakness of which was its unevenness and major omissions of coverage. There was nothing on the 3.4 million square kilometres of karst in China, for example, arguably the most important karst region of the northern hemisphere (and the planet). This new volume edited by Yuan Daoxian \& Liu Zaihua, two wellknown karst specialists from the internationally recognized Institute of Karst Geology in Guilin, China, is more comprehensive in regional coverage but still incomplete, which is not a criticism of the editors but of the failure of potential authors (like me) to provide material. Six chapters deal with aspects of European karst, three are concerned with Asian countries, one with Australasia, and two with selected karst regions in North and South America. There are no chapters on the extensive karsts of Africa or the Middle East, and major karst areas of the Americas and southeast Asia are omitted from consideration. Of the extensive karsts in European and Asiatic Russia, only that of the Urals is covered, although a useful map of karst in the former USSR is presented as Figure 1-9.

These major gaps would inevitably reduce the value of the book if its objective were a comprehensive world survey but, as its title indicates, 'correlation' is more important than coverage, although the actual content of the book suggests comparison to be a more accurate description of its accomplishment.

The objectives of IGCP 299 are outlined in Chapter 1 and can be summarized as being to identify differences in sets of karst features found in various environments on the globe, to study the relationships between these features and the process environments in which they formed, to reconstruct palaeoenvironmental changes from karst records, and to apply the knowledge gained to various karst areas. Underlying these objectives is the implicit understanding that sustainable development of karst terrains and resources depends largely on our knowledge of karst systems and on an appreciation of the particularities of development according to controls imposed by climate and lithology.

Four of the book's sixteen chapters are thematic rather than regional. The first chapter is concerned with basic ideas, methodologies and results of the project; and the second chapter deals with basic physical and chemical principles determining karst evolution, with the aim of increasing our understanding of why karsts look so different under different climatic and geological settings. This chapter provides a valuable insight into the processes initiating subterranean karst network development, into limestone dissolution rates, and into karst conduit evolution from phreatic to vadose stages; but the capacity to explain distinctive landform styles under different climatic regimes remains elusive.

After this introduction, the next twelve chapters describe karsts from Europe (Spitsbergen, Baltic Republics, Great Britain, Romania, Slovenia), Asia (China, Japan, Vietnam), the Ural Mountains between Europe and Asia, Australasia (Australia and Papua New Guinea), and the Americas (eastern USA, western Brazil). A particularly useful attribute of these contributions is the presentation of up-to-date descriptions of karsts that often do not feature in the international literature, for example, Vietnam, Baltic States, Brazil, the Urals and Spitsbergen. The chapters on Spitsbergen, and the Urals are particularly comprehensive, and both involve karsts in a high-arctic permafrozen state, and so may serve as in situ models for other karst areas that have suffered similar conditions in the past. The Ural Mountains extend north to south for about $2000 \mathrm{~km}$ and contain about $300000 \mathrm{~km}^{2}$ of karst developed both on carbonate and sulphate lithologies. The area is associated with considerable mineral and oil exploitation, industry and widespread human impact, and so must constitute one of world's major industrially exploited karst regions.

Contrasting strongly with these high latitude karsts are those of the tropical continental Mato Grosso in western Brazil at latitude $21^{\circ} \mathrm{S}$, described in Chapter 14. Parts of Australasia are also comparatively poorly known, and so Chapter 13 on karst in Australia and Papua New Guinea is particularly welcome and comprehensive, providing the best account of that extensive and contrasting region currently available. The regional descriptions of Great Britain, Japan and Romania are also particularly thorough and valuable.

The book concludes with two thematic chapters. Chapter 15 is devoted to the interpretation of palaeoenvironmental records from luminescent signals in Holocene speleothems, using examples from Bulgaria, Canada and the USA. There is no doubt that the luminescent record of many vadose speleothems contains a wealth of palaeoenvironmental information and that progress is being made in interpreting it, growing evidence suggesting a good correlation with $\delta^{13} \mathrm{C}$ for example. But other work shows we still have a long way to go before the technique can yield unambiguous proxy records that can be correlated significantly with climatic variables.

A short chapter by one of the editors (Yuan Daoxian) entitled "Perspectives of Karst Science" rounds off the book. Although he concludes that "An all-round understanding on the characteristics of karst environmental system was achieved through world correlation" (p.294), I find this rather optimistic except at a qualitative level. The book is certainly one of the sources that demonstrates that we are gradually achieving a greater understanding of karst systems around the world, but there is clearly still a long way to go even to understand quantitatively the influence of climate on karst (though the modelling in Chapter 2 shows we are making progress). Nevertheless, I cannot quarrel with the assertion that gaining an allround understanding "will help more reasonable land use and sustainable development in karst areas". This is certainly one of the major challenges facing karst researchers.

In conclusion, this book has more to do with karst comparison than with explicit correlation, which is perhaps more a criticism of its title than its content. Its coverage of world karsts is patchy, but nonetheless wide ranging, and it incorporates descriptions of karsts not easily accessible in other literature. Together with other works it helps paint the picture of world karsts and, like them, reminds us through its gaps that there's still much to be done before we really understand the nature of karst and can ensure its sustainable development.

\section{Paul W. Williams}

Professor of Geography,

University of Auckland,

New Zealand 


\section{Annual Review of Earth and Planetary Sciences, Volume 26}

\author{
Edited by R. Jeanloz, A.L. Albee \\ and K.C. Burke
}

\author{
Annual Reviews, California, 1998. \\ $771 \mathrm{pp}$., hardbound. US\$75.00 \\ (individual), US\$ 150.00 (institutional). \\ ISBN 0-8243-2026-3.
}

This volume consists of 19 articles, and spans a broad range of research fields, from protoplanetary astronomy, marine geology, and metamorphic petrology to paleoecology, rock mechanics, paleoclimatology and volcanology. As in previous volumes of this series, there is no theme linking the articles to each other and the order of presentation appears to be random. The variety of fields covered by the articles is so extensive that it is impossible to review them adequately. To provide readers with an overview of this volume, however, I list here the names of the authors of each chapter with my preferred classification and introduce its content with a few sentences.

As is the custom, the volume begins with reminiscences of a distinguished scientist, in this case, George Wetherill, with the title "Contemplation of things past". This is the third article that he has written as a preface to the series summarizing his experiences in a field of science and his views on its development.

There are three articles dealing with planetary sciences. F. Nimmo and D. McKenzie review recent developments in the study of volcanism and tectonics on Venus and point out that most of the differences between the processes on Earth and on Venus can be explained by the absence of water. A.P. Boss focuses on theoretical models of temperatures in protoplanetary disks undergoing the accretion of mass from an infalling cloud envelope, which predict a moderately warm $(500$ to $1500 \mathrm{~K})$ inner disk surrounded by a cool (50 to $100 \mathrm{~K}$ ) outer disk. E. Zimmer concentrates on the isotopic composition of presolar dust grains from primitive meteorites and discusses the implications for steller nucleosyntheses.

Four articles deal with low temperature geological processes. T.S. Liu and Z.L. Ding review recent studies of paleomonsoons in East Asia by focusing on monsoon changes in the Quaternary and interactions of monsoons and other parts of climate system. The dynamical relationship is addressed between changes in the regional monsoon circulation and the global climate system. A. Rinaldo I. Rodrignez-Iturbe and R. Rogon summarize their progress in the description of self organization through channel network models in weathered silicate, address the implications of a class of synthetic models and optimal channel networks, and discuss the thermodynamics of networks and the implications of dynamic accessibility of optimal configurations. C.C. Labandeira reviews the early history of arthropods relevant to vascular plant associations and shows that the spectrum of herbivores associated with the Paleozoic Entomofauna occupied almost all of the same ecological niches as ecologically analogous taxis of the Modern Entomofauna. S.L. Wing and L.D. Boucher summarize where Cretaceous angiosperms lived, how they survived, and discuss the implications for their evolutionary success by placing the inferred ecological strategies of Cretaceous flowering plants in the context of strategies observed in living plants.

Geochemistry is the subject of six articles. S. Self, L. Keszthelyi and Th. Thordarson review the importance of pahoehoe lava flows and demonstrate that inflated pahoehoe flows are common in every type of basaltic volcanic terrane. Mounting evidence has shown that large basaltic eruptions can cause major atmospheric perturbations, and their relationship to the mass extinction of fauna is discussed. L.A. Farley and E. Neroda present a summary of noble gas data in mantle samples and discuss their geochemical implications for planetary differentiation, mantle and atmospheric evolution and the relationship between the two. J.M. Ferry and M.L. Gerdes review the isotopic, mineralogical and chemical evidence for reactive fluid flow in contact with regional metamorphic rocks of the continental crust and summarize selected analytical and numerical models used to interpret the evidence in terms of the fundamental properties of the flow system and the current knowledge of metamorphic fluid flow.

Volumes in this series normally focus on short, topical articles that are more of an entree to the field and an indication of the subject's significance than an encyclopedic review. However, this volume contains an unusually long overview by S.B. Shirey and R.J. Walker on Re-Os geochemistry and its applications to cosmochemistry, mantle geochemistry and the origin of noble metal bearing ore deposits. This may be due to the fact that not only is Re-Os geochemistry an exciting new development in science, but that soon it will no longer be possible to review this topic in a single article.

K. Gallagher, R. Brown and C. Johnson review recent progress in fission track analysis and its applications to a variety of geological problems, including sedimentary provenance, thermal history modeling of sedimentary basins, structural evolution of orogenic belts, and long-term continental denudation. P.L. Koch summarizes methods of reconstructing continental climates and environments by means of stable isotope analysis of fossil vertebrates, authigenic minerals and organic matter associated with fossils in paleosols.

There are five articles dealing with geophysics. Satellite altimetry has enabled pro- gress in many areas of geodesy, geophysics, meteorology, orbit physics and so on. C. Wunsch and D. Stammer outline the basic physical considerations of satellite altimetry and describe major findings concerning oceanic general circulation. Recent availability of extremely accurate and high precision satellite altimetry has graphically demonstrated that the ocean is actually a rapidly time-evolving turbulent flow field. W.H.F. Smith reviews the satellite altimetry technique and its resolution of tectonic structures in the seafloor tectonic fabric, gives examples of intriguing tectonic phenomena, and shows that structures as well as abyssal hills are partially resolved. J. Bloxham reviews recent developments in the dynamics of angular momentum balance in the earth's core, which range from numerical studies of the geodynamo to sedimentological studies of differential rotation of the inner core and studies of gravitational coupling between the inner core and mantle. R.G. Gordon examines the central assumption of plate tectonics, that plate interiors are rigid, and discusses plate nonrigidity, diffuse plate boundaries and global plate reconstruction as well as the rate of plate movement. C. Marone presents a review of laboratory derived friction laws and their application to seismic faulting by considering the effects of fault gouge and strain on friction behavior and constitutive parameters and their implications for the sealing problem.

All the articles in the volume are wellwritten and adequately illustrated. They give the readers an insight into the current level of understanding of a wide variety of fields in the earth and planetary sciences. Those readers interested in any of the phenomena described above are encouraged to read the particular article. There they will find not only an excellent review of the subject matter, but also a representative bibliography on the subject that can be used to look for primary sources.

\section{Yong-Fei Zheng}

Department of Earth and Space Sciences University of Science and Technology of China

Hefei 230026

China 